\title{
LOS LÍMITES SOCIALES DE CAZADORES RECOLECTORES DE LA CUENCA INFERIOR DEL RÍO PARANÁ. UN ANÁLISIS ESTILÍSTICO DE LA ALFARERÍA
}

\author{
SOCIAL BOUNDARIES OF HUNTER GATHERER GROUPS IN THE LOWER \\ PARANA BASIN. A STYLISTIC ANALYSIS OF POTTERY
}

\author{
Sheila Ali ${ }^{1}$ \\ ${ }^{1}$ CONICET - INAPL. 3 de febrero 1378, CABA. sheilagriselali@yahoo.com.ar
}

Presentado: $15 / 06 / 2020$

Aceptado: 24/02/2021

\section{Resumen}

Los grupos cazadores recolectores que habitaron la cuenca inferior del río Paraná han producido una gran cantidad de vasijas cerámicas usadas para cocinar, almacenar y transportar alimentos. Estas piezas han sido reconstruidas a partir de fragmentos como cuencos o escudillas de formas abiertas y contornos simples. Si bien la forma de manufactura ha reflejado prácticas compartidas, la decoración presenta una mayor variabilidad. En este trabajo el objetivo es analizar cómo ha actuado el estilo en la alfarería entre los grupos cazadores recolectores, tomando en consideración el modelo planteado para la zona que sostiene un aumento demográfico durante el final del Holoceno tardío, con un pico alrededor de 1100 AP, e incentivó paralelamente una mayor fragmentación social. Se plantea como hipótesis principal que los rasgos más visibles de las vasijas, tales como las representaciones iconográficas, pudieron ser empleadas para reflejar el establecimiento de límites sociales más estrictos. En este sentido, se comparan las colecciones cerámicas de cuatro sitios (Médanos de Escobar, Túmulo de Campana 2. Anahí, Punta Canal) que permiten abordar un rango cronológico extendido para comparar las técnicas decorativas y los motivos estilísticos a lo largo de este proceso. Se espera encontrar a partir de los $1100{ }^{14} \mathrm{C}$ años AP, una mayor estandarización de las técnicas decorativas y la presencia de motivos más complejos con la finalidad de construir un estilo homogéneo y distintivo.

Palabras claves: cazadores-recolectores, cerámica, estilo, identidad.

\begin{abstract}
The hunter-gatherer groups that had inhabite the lower Paraná basin have produced a large number of ceramic vessels used for cooking, storing and transporting food. These pieces have been reconstructed as bowls with open shapes and simple contours. Although the way of manufacture has reflected shared practices, the decoration presents a greater variability. In this work, the objective is to analyze how the style has acted in pottery among the hunter-gatherer groups, taking into account the model proposed for the area that sustain a demographic increase
\end{abstract}


that began approximately 1100 years ago, which encouraged a further social fragmentation. The main hypothesis propose that the most visible aspects of the vessels, such as iconographic representations, can be used to reflect the establishment of stricter social boundaries. In this sense, the ceramic collections of four sites (Médanos de Escobar, Túmulo de Campana 2, Anahí, Punta Canal) are compared, which allows us to broach an extended chronological range to analyze decorative techniques and stylistic motifs throughout this process. It is expected to find, from the 1100 years BP, a greater standardization of decorative techniques and the presence of more complex motifs with the objetive of building a homogeneous and distinctive style.

Key Words: Hunter gatherers, pottery, style, social boundaries.

\section{Introducción}

Desde hace 2500 años, la cuenca inferior del río Paraná fue densamente habitada por grupos cazadores recolectores complejos que basaban su economía principalmente en la pesca y también en la caza y la recolección (Loponte y Acosta 2003). Los ambientes de humedales, como los que dominan el área, se caracterizan por poseer una elevada productividad que, en este caso, es regulada por el régimen hídrico del río Paraná (Malvárez 1999). La presencia de recursos altamente predecibles y circunscriptos en el espacio les permitió a estas poblaciones tener una movilidad residencial reducida derivando conductas territoriales (Acosta et al. 2010, Loponte 2008, Loponte et al. 2004). Las estrategias de aprovechamiento del ambiente de estos grupos reflejan una intensificación en la explotación de recursos y la producción de equipos tecnológicos sofisticados que buscaron maximizar su obtención y procesamiento (Silvestre et al. 2013). Dentro de estas tecnologías de alto costo puede destacarse también la producción de alfarería.

En este trabajo se analizará, en particular, el sector denominado "Bajíos Ribereños meridionales" (en adelante "BRM"), que comprende el sector continental bonaerense emplazado en la margen derecha del río Paraná y que abarca los actuales partidos de Campana, Escobar y Tigre (Figura 1). Esta zona durante los momentos de ocupación humana, a partir de los 2500 años ${ }^{14} \mathrm{C}$ AP, constituía parte de la costa del estuario superior del Río de la Plata, ya que una gran parte de la porción inferior del Delta se conformó entre los años 1000 y 1500 años ${ }^{14} \mathrm{C}$ AP (Loponte 2008). El modelo propuesto para la zona plantea un escenario de aumento demográfico que intensificó una mayor fragmentación social y competencia por explotar los espacios más productivos hace aproximadamente 1100 años ${ }^{14} \mathrm{C}$ AP (Loponte 2008). Si bien la alfarería posee una continuidad en la composición y manufactura, las técnicas decorativas y los motivos estilísticos presentan mayores diferencias a través del tiempo y el espacio. En este trabajo me propongo analizar las representaciones iconográficas presentes en la cerámica con el objetivo de comprender si fueron empleadas en el pasado para transmitir y definir límites sociales entre diferentes grupos humanos. 


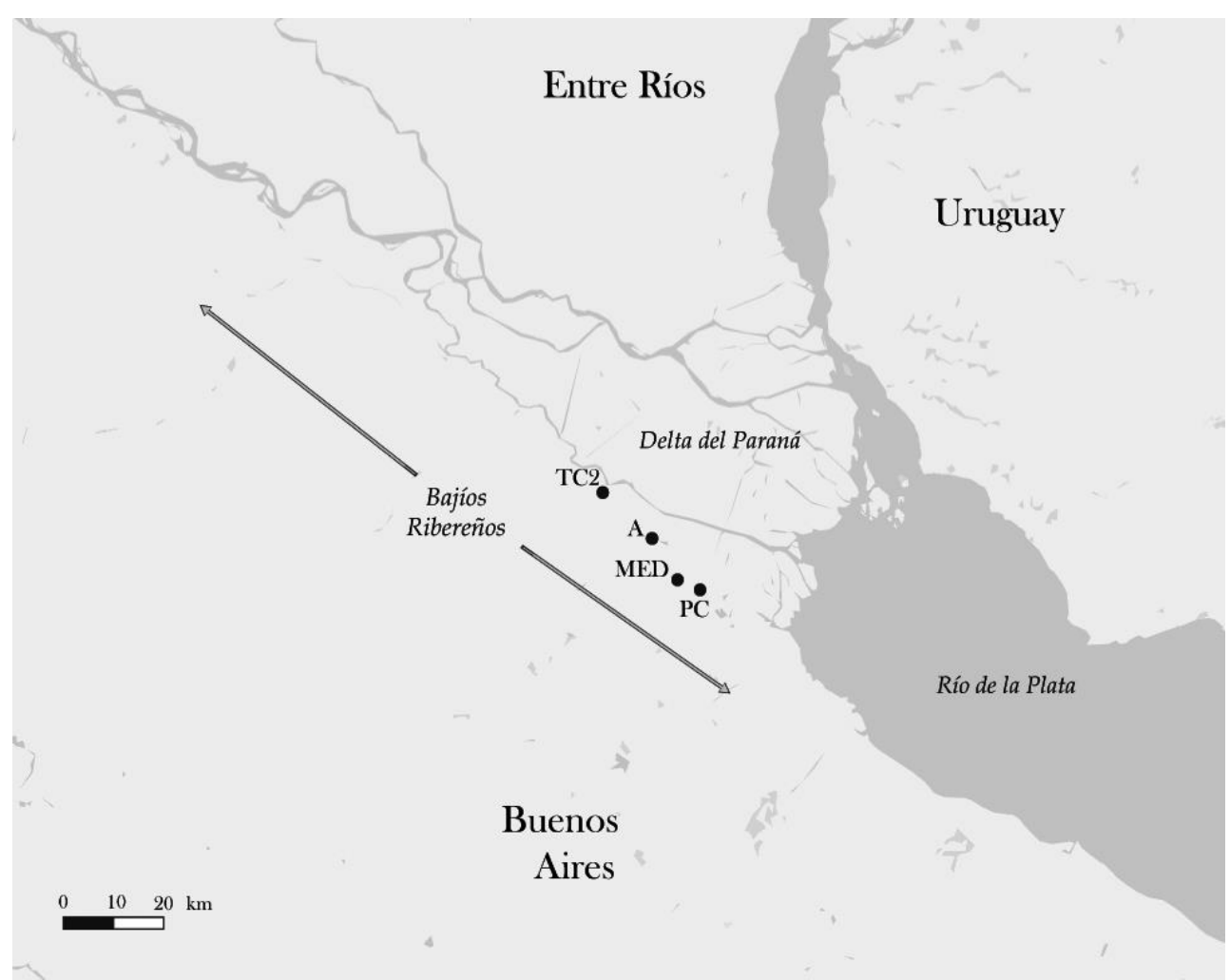

Figura 1. Mapa con ubicación de los sitios arqueológicos analizados. TC2: Túmulo de Campana sitio 2. A: Anahí. MED: Médanos de Escobar. PC: Punta Canal.

El análisis estilístico de la alfarería ha tenido un rol central desde los inicios de las investigaciones en la zona hacia finales del siglo XIX (Ameghino 1947 [1880]; Torres 1911; Lothrop 1932). La mayor parte de las aproximaciones se focalizaron en los aspectos decorativos e iconográficos de la cerámica con la finalidad de establecer cronologías y unidades culturales vinculadas con grupos etnográficos. Sin embargo, en las últimas décadas con la expansión de la Nueva Arqueología, las investigaciones arqueológicas se centraron en los análisis de subsistencia y estudios tecnológicos. En la cuenca inferior del río Paraná, las investigaciones arqueológicas de la alfarería se desenvolvieron sobre aspectos de producción y uso (Pérez y Cañardo 2004) y se desarrollaron distintas aproximaciones arqueométricas tales como: análisis petrográficos (Pérez y Montenegro 2009; Ottalagano y Pérez 2013), análisis de ácidos grasos (Naranjo et al. 2010; Pérez et al. 2013) y, recientemente, espectroscopía de fluorescencia de rayos X (Loponte et al. 2019b). Esta línea de investigación ha reflejado una gran homogeneidad en las prácticas alfareras de los grupos cazadores recolectores y un mayor contraste con la producción cerámica de los grupos horticultores amazónicos (etnográficamente denominados "guaraníes") que arribaron a la zona hace alrededor de 700 años ${ }^{14} \mathrm{C}$ AP (Loponte y Acosta 2003). Sin embargo, el estudio de los aspectos estilísticos de la alfarería ha tenido un rol secundario en las investigaciones de los últimos años.

En este escenario, ciertos elementos de diseño reconocidos en la alfarería de la macrorregión abordada habrían funcionado como diacríticos de interacción social, es decir, como un medio para reforzar relaciones de intercambio entre diferentes grupos. 
En este sentido, el objetivo propuesto en este trabajo consiste en analizar las técnicas decorativas y los motivos de los conjuntos alfareros de los sitios arqueológicos Médanos de Escobar, Túmulo de Campana 2 (colección Lafon), Anahí y Punta Canal. Estos sitios permiten realizar un análisis dentro de un rango cronológico extendido que abarca desde los 1800 hasta los 900 años ${ }^{14} \mathrm{C} \mathrm{AP}$, por lo que permite observar los cambios o continuidades de las representaciones iconográficas en la alfarería a través del período de aumento demográfico iniciado hace 1100 años ${ }^{14} \mathrm{C}$ AP.

El estilo en arqueología ha sido ampliamente discutido a lo largo del desarrollo de la disciplina (arqueología procesual: Binford 1965; teoría evolutiva: Dunnell 1978; arqueología posprocesual: Dietler y Herbich 1998, teoría de la comunicación: Wiessner 1983; Wobst 1977; antropología de la tecnología: Lechtman 1977; Lemmonier 1986; Sackett 1986; entre otros). En este trabajo se adopta una perspectiva evolutiva que define a la cultura como información socialmente aprendida, sobre la cual operan diferentes fuerzas evolutivas, que producen patrones diferentes y distinguibles entre sí (Dunnell 1989; Shennan 2003; Richerson y Boyd 2005). Si bien se ha planteado que el estilo posee un carácter neutral (Dunnell 1989; Neiman 1995), en los últimos años este postulado comenzó a discutirse (Shennan y Wilkinson 2001). Siguiendo el modelo de Neiman (1995) que plantea que los factores que afectan al estilo son los tamaños de población y las tasas de innovación, se plantea que en caso de que el estilo haya tenido un rol neutral a lo largo del tiempo se esperará que ante un aumento demográfico la diversidad estilística sea mayor. Por lo tanto, si la población aumentase y la tasa de innovación se mantuviese constante, la diversidad estilística debería ser mayor en el bloque temporal tardío. Este postulado funciona en este trabajo como hipótesis nula. Por otra parte, la hipótesis principal que se sostiene es que, en el bloque temporal tardío, la distribución tendrá un patrón direccional y marcado resultado de la acción de la transmisión sesgada por frecuencia o "transmisión conformista". Kohler et al. (2004) plantean que bajo determinadas situaciones un individuo seleccionará el modelo más común para imitar. Este tipo de transmisión en poblaciones de tamaños grandes permite evitar el costo de aprendizaje individual y este mecanismo también produce una disminución de la variabilidad.

En el caso de la hipótesis nula se espera encontrar un patrón aleatorio y no direccional de rasgos decorativos e iconográficos a lo largo del tiempo. Este escenario no implica que dichos rasgos constituyan un antecedente de aquellos que se observarán en los sitios más tardíos. La elevada variabilidad de cada conjunto puede ser resultado de elecciones individuales dentro de una comunidad que no impone normas estrictas que regulen la transmisión de información identitaria social a través de la cerámica o reflejar una estructura de normas particulares para cada conjunto. En cambio, en la hipótesis principal se espera encontrar en los sitios tardíos un patrón direccional y marcado reflejado en una elevada estandarización de las técnicas decorativas y la presencia de motivos complejos diferenciables entre distintas unidades arqueológicas que permitan demarcar una mayor diferenciación externa al grupo y una menor diferenciación hacia el interior del mismo. 


\section{La alfarería de los cazadores recolectores de la cuenca inferior del río Paraná}

La cerámica, junto con los restos arqueofaunísticos, constituyen los materiales más abundantes del registro arqueológico de la zona. La incorporación de esta tecnología en los grupos cazadores recolectores permitió potenciar el aprovechamiento de recursos vegetales y animales disponibles en el ambiente del humedal a través del empleo de la técnica del hervido, de prácticas de almacenamiento y, también, en el transporte de agua y alimentos (Pérez y Cañardo 2004; Acosta y Pafundi 2005; Naranjo et al. 2010; Pérez et al. 2012; Pérez et al. 2015). En este sentido, a partir de fuentes etnográficas (Férnandez de Oviedo y Váldez 1944; Schmidl 1948) se describe la utilización de manteca y harina de pescado, las cuales podrían tener un consumo diferido a través del almacenamiento de las mismas. Además, la elevada fragmentación de restos óseos de especies tales como $M$. coypus reflejan la utilización del hervido para cocinar los alimentos (Loponte et al. 2012).

Las vasijas producidas por estos grupos han sido reconstruidas como escudillas de perfiles abiertos, con contornos simples (Caggiano et al. 2001; Loponte 2008; Pérez 2010). En menores proporciones se recuperaron alfarerías denominadas "tubulares" o "alfarerías gruesas" y escasos modelados zoomorfos en los sitios Túmulo de Campana 1, Garín y Arroyo Sarandí (Loponte 2008). Los análisis petrográficos llevados a cabo en los últimos años (Pérez y Montenegro 2009; Capdepont y Bonomo 2013; Ottalagano y Pérez 2013) permitieron determinar que las arcillas empleadas para confeccionar la cerámica se encuentran disponibles en el ambiente del humedal, lo cual, junto con la presencia de bollos pequeños sin quemar en el registro arqueológico, permiten asumir que la producción de la misma fue local. Además se ha determinado que las pastas están compuestas por minerales presentes en los barros arcillosos de la zona pero también por tiestos molidos que pudieron ser adicionados de forma intencional como antiplásticos. Con respecto a las etapas de manufactura, se constató la utilización de la técnica de rollos y el modelado (Pérez y Cañardo 2004; Loponte 2008).

La decoración de la alfarería se encuentra restringida, en la mayoría de los casos, al sector de bordes. Entre las técnicas decorativas empleadas se encuentran la incisión y la pintura y los motivos estilísticos están constituidos en su totalidad por figuras geométricas. A diferencia de otras acciones involucradas en la producción de una vasija, las representaciones iconográficas presentan una importante variabilidad dentro del interior de los grupos cazadores recolectores. Rodrigué (2005) ha analizado la decoración en la alfarería de la zona y plantea la presencia de tres grandes grupos cerámicos: el primero se compone de cerámica lisa y su producción se atribuye a grupos cazadores recolectores, el segundo contiene cerámica decorada con incisión y también se vincula con grupos cazadores recolectores $\mathrm{y}$, por último, el tercer grupo posee cerámica corrugada y se relaciona con los grupos conocidos etnográficamente como guaraníes. Estos conjuntos cerámicos pueden vincularse directamente con el modelo que sostiene la existencia de dos linajes que se solaparon en tiempo y espacio y aparecen bien marcados durante finales del Holoceno tardío (Loponte 2008; Loponte et al. 2012). El primero ("linaje 1"denominado informalmente como "Grupo de Cerámica 
Incisa") ha sido caracterizado por poseer menor incidencia de peces en la dieta, ausencia de tembetás en forma de $\mathrm{T}$, uso de mayor cantidad de instrumentos líticos y presencia de cerámica decorada, entre otros rasgos. Contrariamente, el segundo linaje ("linaje 2", también informalmente de denominado "Grupo de Cerámica Lisa") posee mayor incidencia de peces en la subsistencia, empleo de tembetás en forma de $T$, escaso o nulo uso de materia prima lítica y la manufactura y presencia de cerámica lisa. También se han observado diferentes cambios entésicos y distintos valores isotópicos de las dietas entre los humanos recuperados de estos dos grandes grupos, como así también diferencias significativas en el estilo y frecuencia de decoración de los artefactos óseos (Buc 2019; Mazza 2019; Loponte 2020).

En este trabajo se plantea una dinámica social de mayor complejidad a partir de los 1100 años AP debido a un aumento demográfico que derivó en una mayor competencia por los espacios productivos. Este planteo busca concebir al escenario social del HPI dentro de una visión dinámica, en la cual la conformación de límites sociales se construyó a lo largo del tiempo de diferentes maneras y por diferentes factores sociales. Se ha planteado que las situaciones de contacto e intercambio se encuentran reguladas socialmente entre los grupos, es decir, por un lado existen situaciones permitidas de articulación dentro de determinadas actividades y, por otro lado, hay sanciones que prohíben la interacción aislando ciertos segmentos de la cultura de posibles confrontaciones o modificaciones (Barth 1976:18). En el caso del estilo alfarero, considero que pudo ser una vía para expresar la demarcación de una diferencia con el "otro" y una identificación con el "nosotros". Estas normas deben ser entendidas por ambos grupos y revalidadas subjetivamente. En estos casos donde pudieron existir principios que regulen las identidades sociales, Barth plantea que existirá la tendencia a la canalización y estandarización de la interacción y a la aparición de límites que mantienen y generan la diversidad étnica dentro de los sistemas sociales circundantes más amplios (Barth 1976: 21-22).

\section{Materiales y métodos}

Se han analizado las colecciones cerámicas de cuatro sitios arqueológicos: Túmulo de Campana 2 (colección Lafon), Médanos de Escobar, Anahí y Punta Canal. Todos ellos han sido definidos como espacios multifuncionales y se han realizado estudios tafonómicos que permiten controlar la muestra analizada (Loponte 2008; Acosta et al. 2013; Tchilingurián 2013). La estratigrafía, en todos los casos, constituye un registro promediado de actividades (Loponte y Acosta 2003) que refleja un conjunto de actividades domésticas llevadas a cabo durante un rango temporal específico, acotado a través de los fechados radiocarbónicos realizados en cada uno de los sitios. La ausencia de laminación que poseen los suelos del área impide identificar unidades microestratigráficas discretas, por esta razón se considera a los depósitos como palimpsestos cuyas potencias máximas promedio oscilan entre 50 y $60 \mathrm{~cm}$ (Loponte 2008). Los remontajes de las vasijas demuestran que los sitios que se incluyen aquí constituyen un evento central de descarte o varios escasamente separados en el tiempo 
y que no pueden diferenciarse en términos estratigráficos ni estilísticos. Otros aspectos que apoyan este postulado son la existencia de perfiles similares de meteorización, la distribución continua de materiales arqueológicos y la ausencia de diferencias tecnoestilísticas en la alfarería observada a nivel intrasitio (Loponte 2008). Si bien en los sitios arqueológicos aquí analizados se cuenta con un solo fechado radiocarbónico en cada caso, otros sitios de la zona ${ }^{1}$ con mayor cantidad de fechados han demostrado edades radiocarbónicas supuerpuestas en cada uno de ellos, reforzando la idea de que estas unidades estratigráficas homogéneas y discretas representan un evento de descarte o varios escasamente separados en el tiempo. Por lo tanto, podemos asumir que el fechado radiocarbónico obtenido para cada sitio es representativo del contexto recuperado en cada uno de ellos.

El análisis de estos cuatro sitios arqueológicos permite abordar un período cronológico extendido que abarca desde los 1800 a los 600 años ${ }^{14} \mathrm{C}$ AP para comparar los patrones decorativos durante la etapa anterior y posterior a los 1100 años ${ }^{14} \mathrm{C}$ AP. Entonces, puede establecerse que en el bloque temporal temprano (1800-1100 años ${ }^{14} \mathrm{C}$ $\mathrm{AP}$ ) se incluyen las colecciones cerámicas de Túmulo de Campana 2 y Médanos de Escobar y en el bloque tardío (1100-600 años ${ }^{14} \mathrm{C}$ AP), los sitios Anahí y Punta Canal (Tabla 1).

\begin{tabular}{|c|c|c|c|c|c|}
\hline Sitios & Edad ${ }^{14} \mathbf{C}$ & $\begin{array}{c}\text { Fechado } \\
\text { calibrado }\end{array}$ & Taxa & Lab. & $\begin{array}{c}\text { N } \\
\text { tiestos }\end{array}$ \\
\hline $\begin{array}{c}\text { Médanos } \\
\text { de Escobar }\end{array}$ & $\begin{array}{c}1752 \pm 33 \\
\text { (Acosta } \text { et al. } 2013)\end{array}$ & - & $\begin{array}{c}\text { B. } \\
\text { dichotomus }\end{array}$ & AA97465 & 7765 \\
\hline $\begin{array}{c}\text { Túmulo de } \\
\text { Campana 2 }\end{array}$ & $\begin{array}{c}1640 \pm 70 \\
\text { (Loponte } 2008)\end{array}$ & - & Mammalia & Beta 172059 & 3032 \\
\hline Anahí & $\begin{array}{c}1020 \pm 70 \\
\text { (Loponte } 2008)\end{array}$ & $\begin{array}{c}1017- \\
1151(\mathrm{p}=1)\end{array}$ & $\begin{array}{c}\text { Myocastor } \\
\text { coypus }\end{array}$ & Beta147108 & 8948 \\
\hline $\begin{array}{c}\text { Punta } \\
\text { Canal }\end{array}$ & $\begin{array}{c}900 \pm 80 \\
\text { (Arrizurieta } \text { et al. } \\
2010)\end{array}$ & $\begin{array}{c}1026-1283 \\
\mathrm{AD}(\mathrm{p}=1)\end{array}$ & $\begin{array}{c}\text { B. } \\
\text { dichotomus }\end{array}$ & LP-1293 & 12329 \\
\hline
\end{tabular}

Tabla 1. Fechados radiocarbónicos de cada sitio y cantidad de fragmentos que componen cada colección cerámica.

Debido a la elevada fragmentación de las colecciones cerámicas, la unidad de análisis empleada en este trabajo se encuentra definida por fragmento de cerámica o tiesto y no por vasija. Se han realizado tareas de remontaje que resultaron más exitosas en bordes decorados, pero los ensamblajes son más complejos para los sectores lisos de los cuerpos. Actualmente, se está avanzando en el uso de "Equivalentes de Vasijas Estimadas" ("EVE" sensu Orton et al. 1997), que define a cada fragmento como una porción de la vasija completa y se calcula a partir del porcentaje del fragmento respecto a los $360^{\circ}$ del total de la circunferencia de boca (Orton et al. 1997; Adroher Auroux et al. 2016). En este caso se analizan solamente los fragmentos de bordes y se toma en consideración los remontajes realizados. En Médanos de Escobar las vasijas estimadas son 41 sobre un total de 1209 bordes y en 
Túmulo de Campana 2 se estimaron 15 a partir de 421 bordes. En el caso Anahí y Punta Canal esta estimación se encuentra en proceso de análisis, en el primer caso se han calculado 39 vasijas sobre un total de 982 bordes que equivalen al $60 \%$ del total de esta muestra y, en el segundo caso, sólo se ha analizado un $15 \%$ de la muestra que representa 13 vasijas sobre un total de 288 bordes. Estos resultados preliminares sugieren una mayor fragmentación en el sitio Punta Canal aunque se debe tomar con recaudos ya que la muestra analizada es todavía muy escasa y, por lo tanto, puede no ser representativa del conjunto.

En términos generales, se ha observado que la decoración de las vasijas se encuentra restringida al sector de los bordes, con guardas que se establecen de forma paralela a los labios (Torres 1911; Caggiano 1984; Kusch y Conlazo 1984; Rodrigué 2005; Loponte 2008). Las técnicas decorativas que se distinguen son la incisión y la pintura, y los motivos estilísticos están constituidos en su totalidad por figuras geométricas. Tomando en cuenta esta caracterización, se ha decidido dividir el análisis decorativo en dos grandes líneas de análisis: las técnicas decorativas, tales como la incisión y la pintura, y los motivos estilísticos, a través del uso de unidades mínimas de diseño. Estas unidades fueron definidas a partir de las figuras geométricas identificadas en los tiestos y los motivos fueron determinados por la relación del contenido o tema y la técnica de incisión empleada, es decir, las figuras geométricas y la forma de ejecución.

Con respecto a las técnicas de incisión, se ha tomado la clasificación de Rodrigué (2005: 64) que define seis variantes: línea contínua, surco rítmico, quebrado, punteado, unguiculado y corrugado. Se han relevado de forma independiente los tiestos que presentan una sola técnica de incisión y aquellas que tienen técnicas combinadas, tomando a cada combinación de forma independiente.

Por otra parte, en relación con la pintura, se han analizado, por una parte, los colores de los pigmentos para inferir los posibles materiales orgánicos e inorgánicos empleados y, por otra parte, las caras en las que se identifica la presencia de la pintura con la finalidad de reconstruir los sectores de la vasija que fueron elegidos para decorar. El análisis sobre las técnicas decorativas constituye un aspecto importante para comprender las elecciones que han tomado los/as artesanos/as en el pasado.

La segunda línea de análisis a considerar han sido los motivos estilísticos. En este caso, debido al elevado índice de fragmentación que poseen todas las colecciones de la zona (Rodrigué 2005; Loponte 2008), se ha decidido utilizar unidades mínimas de diseño que constituyen una escala menor a la del motivo y pueden ser reconocidas por la repetición de técnicas o figuras dentro de una población determinada (Lechtman 1977). Estas unidades son completas en sí mismas y permiten reconstruir los temas o motivos que son los buscados efectivamente por los artesanos, cualquiera sea su composición, simple o compleja (Aldazábal 2002, 2008; Loponte 2008). Además, debido 
a esta problemática, se ha decidido analizar sólo los bordes, que constituyen los espacios más utilizados para la decoración de las vasijas en la zona (Rodrigué 2005), con la finalidad de evitar una sobreestimación de diseños. Las unidades mínimas de diseño fueron definidas a partir de su contenido, es decir, a partir de la/s figura/s geométrica/s que se observaron en los tiestos. Las unidades de diseño fueron diferenciadas entre simples y complejas según la clasificación de Kusch (1991), la cual sostiene que las unidades simples son aquellas que responden a una sola categoría, en este caso, a una sola figura geométrica, y las complejas, son aquellas que aluden a más de una categoría.

Finalmente, una vez que se han identificado las distintas unidades mínimas de diseño en cada una de las colecciones cerámicas, se buscó determinar motivos estilísticos a partir de la relación de las figuras geométricas y las técnicas de incisión empleadas con mayor frecuencia. Es decir, que si una misma unidad de diseño fue realizada con diferentes técnicas de incisión fueron definidos como dos motivos estilísticos distintos y se observó su trayectoria a través del tiempo de forma separada.

\section{Resultados}

\section{A-Técnicas decorativas}

Las colecciones cerámicas analizadas en este trabajo poseen en todos los casos elevados porcentajes de bordes decorados (Médanos de Escobar= 638, Túmulo de Campana 2= 204, Anahí $=578$, Punta Canal= 279). Se han considerado como "decorados" a aquellos fragmentos que poseen marcas de incisión y/o restos de pintura en alguna de sus caras y no los casos en los que sólo se presentan pequeñas incisiones en los labios, llamadas "muescas" con la finalidad de reducir la muestra hacia aquellos fragmentos donde se analicen las variables de pintura e incisión tomadas en este trabajo. A pesar de poseer una alta proporción de bordes decorados, las técnicas empleadas para decorar los tiestos han sido distintas (Tabla 2). Se observa que en el bloque temporal temprano los porcentajes en los conjuntos analizados de decoración son elevados, aunque las proporciones de las técnicas elegidas son distintas. En el bloque temporal tardío, la situación resulta inversa, en Punta Canal el porcentaje de decoración es menor pero las elecciones técnicas de ambos conjuntos son similares. El bajo porcentaje en Punta Canal puede deberse a una mayor fragmentación de esta colección cerámica y a la incorporación en los conteos de fragmentos más pequeños en comparación con las restantes. 


\begin{tabular}{|c|c|c|c|c|}
\hline & $\begin{array}{c}\text { \% Bordes } \\
\text { incisos }\end{array}$ & $\begin{array}{c}\text { \% Bordes } \\
\text { pintados }\end{array}$ & $\begin{array}{c}\text { \% Bordes } \\
\text { incisos y } \\
\text { pintados }\end{array}$ & $\begin{array}{c}\text { \% Bordes } \\
\text { decorados }\end{array}$ \\
\hline $\begin{array}{c}\text { Médanos de } \\
\text { Escobar }\end{array}$ & 83,15 & 9,4 & 7,45 & $\mathbf{3 0 , 6 9}$ \\
\hline $\begin{array}{c}\text { Túmulo de } \\
\text { Campana 2 }\end{array}$ & 26,63 & 54,21 & 19,16 & $\mathbf{4 8 , 7 5}$ \\
\hline Anahí & 25,43 & 48,79 & 25,78 & $\mathbf{3 3 , 4 8}$ \\
\hline Punta Canal & 31,54 & 43,37 & 25,09 & $\mathbf{1 2 , 1 6}$ \\
\hline
\end{tabular}

Tabla 2. Tabla de bordes decorados en cada colección, con el detalle de las técnicas decorativas empleadas.

En el caso de los fragmentos incisos (Médanos de Escobar $=705$, Túmulo de Campana n= 200, Anahí = 637, Punta Canal = 187) se han relevado para cada conjunto las técnicas empleadas siguiendo la metodología de Rodrigué (2005) (Figura 2). A partir de este análisis se ha observado que en el caso de los conjuntos del bloque temporal temprano existe una amplia variedad de técnicas empleadas, aunque en cada conjunto pueden destacarse técnicas de mayor representación. En la colección de Médanos de Escobar se destaca la técnica de la línea continua con un porcentaje mayor al $50 \%$, en Túmulo de Campana 2 se reflejan valores elevados en la combinación de línea continua y quebrado (38 \%) y en Punta Canal y Anahí el surco rítmico es la técnica predominante con un porcentaje superior al $75 \%$ en ambos.

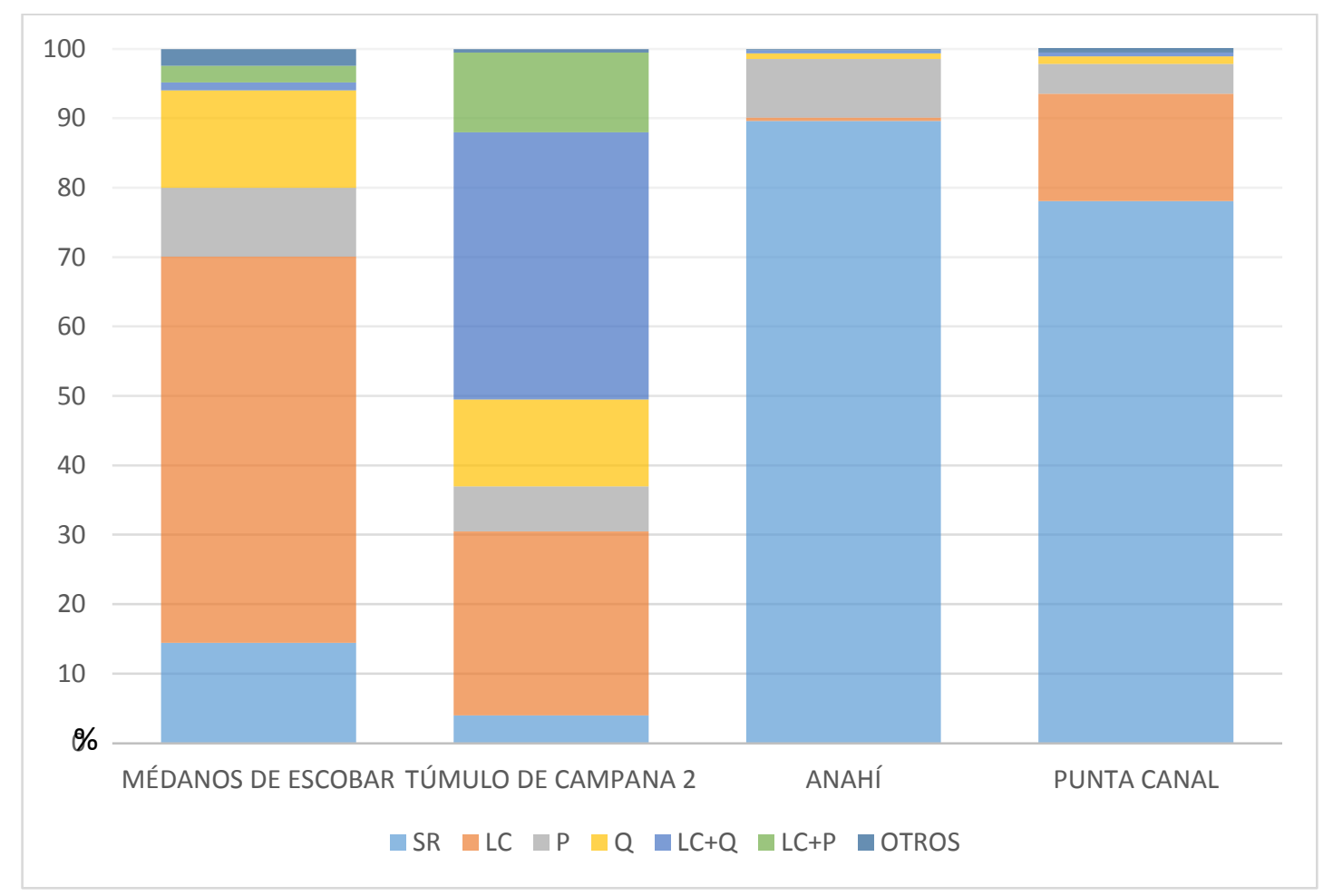

Figura 2. Representación de las técnicas de incisión en cada una de las colecciones analizadas. 
Además de la incisión, la alfarería de los sitios de cazadores recolectores del área está decorada a través de la pintura. El color rojo fue el más utilizado, aunque también se han observado tiestos con pinturas negras en menores proporciones o blancas, principalmente en artefactos tubulares. Estas piezas se diferencian del resto del conjunto cerámico de uso doméstico $\mathrm{y}$, si bien su utilidad ha estado discutida desde comienzos del siglo XX, actualmente se ha planteado su uso dentro de la esfera simbólica de los grupos cazadores recolectores vinculado con prácticas mortuorias (Loponte et al. 2019a). Los análisis realizados a través de la técnica MEB-EDX (microscopía electrónica de barrido y microanálisis por dispersión de energía de rayos-X) en muestras de Túmulo de Campana 2 han permitido aportar datos sobre la caracterización elemental de los pigmentos en su fracción inorgánica. En el caso de las pinturas rojas los niveles elevados de hierro sugieren el uso de óxidos férricos tales como la hematita, en las pinturas blancas se destacan los valores de fósforo y calcio que sugieren el uso de hueso calcinado y, por último, en el caso del pigmento negro la ausencia de niveles elevados de hierro o manganeso plantean la posibilidad del empleo de materiales orgánicos tales como el carbón vegetal (Pérez et al. 2015; Ali et al. 2020). La selección de estas materias primas para confeccionar pigmentos empleados en la decoración cerámica también es observada en otras zonas cercanas tales como la cuenca media del río Paraná (Ottalagano et al. 2015) y la depresión del Salado (Frére et al. 2016).

En relación con las pinturas identificadas en los sitios Médanos de Escobar ( $\mathrm{n}=$ 207), Túmulo de Campana 2 ( $\mathrm{n}=558)$, Anahí ( $\mathrm{n}=1159)$ y Punta Canal ( $=191)$, los resultados reflejan que en todos los casos la pintura roja supera el $80 \%$ de la muestra. Por otra parte, se observa también que los sitios que pertenecen al bloque temporal tardío poseen menor variabilidad de pigmentos y proporciones más elevadas de pintura roja. Si bien la presencia de combinaciones de pigmentos es muy baja, se observa que, la más representada es la que combina los colores rojo y negro (Figura 3).

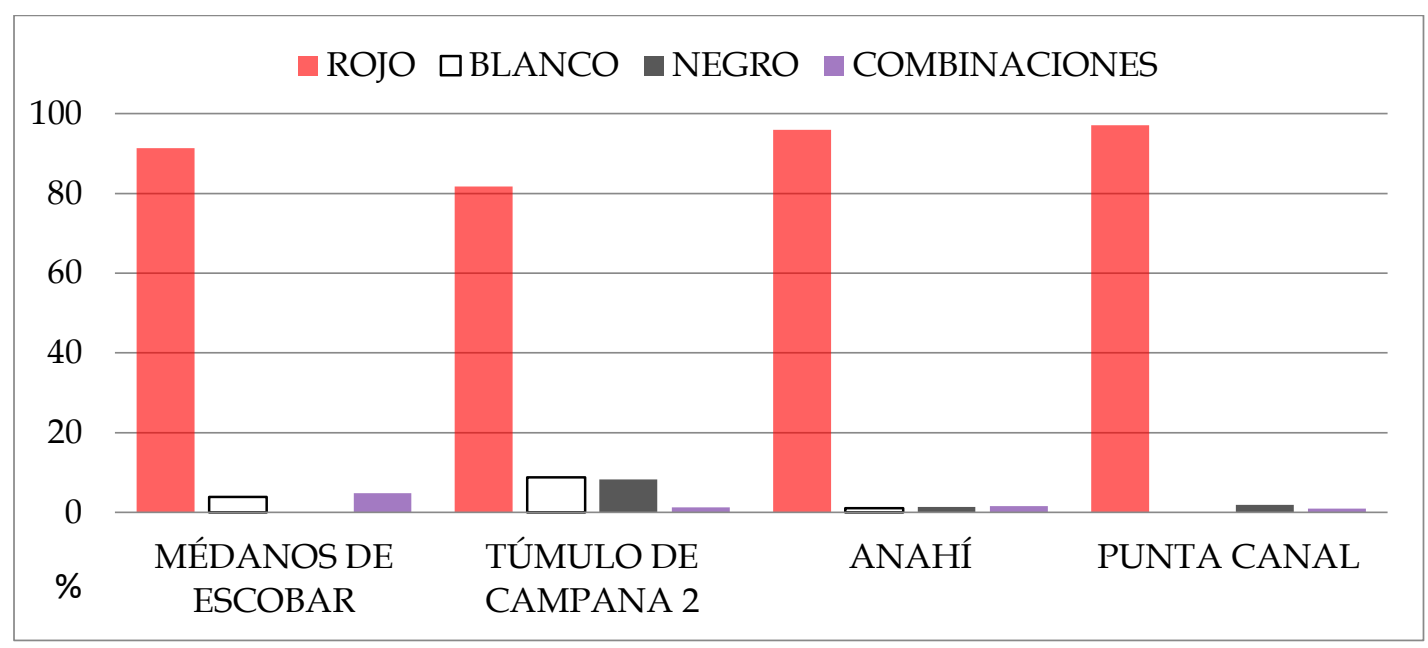

Figura 3. Representación de porcentaje de los distintos colores empleados para decorar las vasijas a través de la pintura. 
Por otra parte, los sectores de la vasija que han sido pintados también reflejan elecciones técnicas tomadas por los/as artesanos/as en el pasado. Para este fin se contabilizaron las caras que presentan pintura en los fragmentos de bordes y cuerpos de cada colección. En este sentido, se observa que en el caso de Médanos de Escobar y Túmulo de Campana 2, los bordes poseen elevadas proporciones de pintura en la cara interna y en ambas, a diferencia de los cuerpos que poseen mayores proporciones en la cara interna solamente. Esto permite pensar que la pintura era aplicada sobre toda la cara interna de la vasija pero sólo en el sector de bordes en la cara externa. Si tenemos en cuenta que las formas de las vasijas en la zona son los cuencos y las escudillas de perfiles abiertos, se comprende que los artesanos buscaban aplicar los pigmentos solamente en aquellas zonas que resultaran más visibles. En el caso de los sitios Anahí y Punta Canal las proporciones de bordes y cuerpos con ambas caras pintadas son notablemente mayores. Por lo que, se plantea que en estos casos las vasijas eran pintadas en el lado exterior de forma más amplia que los casos anteriores (Figura 4).

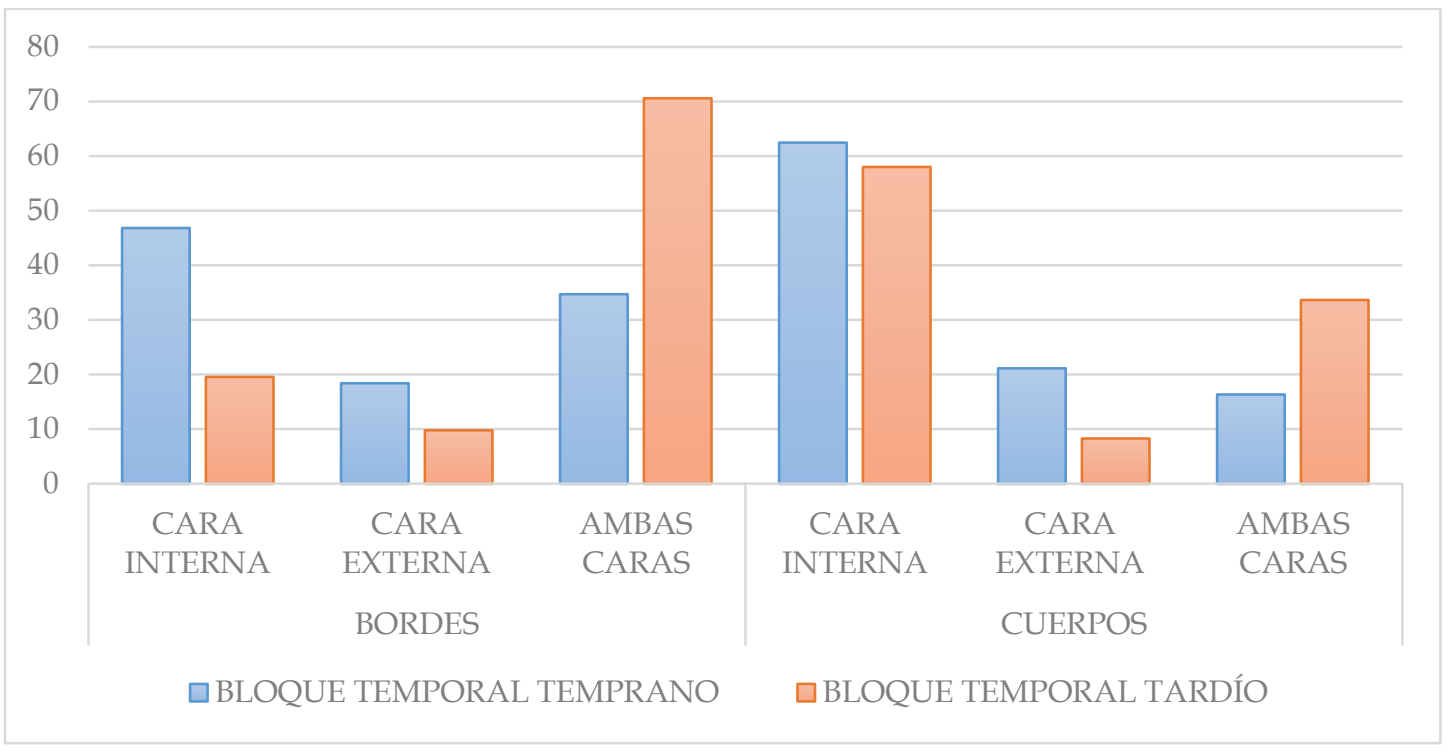

Figura 4. Representación de porcentaje de la presencia de pintura en los distintos sectores de las vasijas.

Por último, se han analizado los fragmentos de bordes y cuerpos en los que se ha empleado la incisión y la pintura en conjunto. En este caso, se observa que en las colecciones de Médanos de Escobar y Túmulo de Campana 2 los porcentajes son bajos y no superan el 11 \%. Sin embargo, en Anahí los valores llegan al 25 \% y en Punta Canal al 65 \% (Figura 5). En este sentido, la aplicación de pinturas sobre los motivos incisos fue una elección tomada y compartida entre los/as artesanos/as del bloque temporal tardío. 


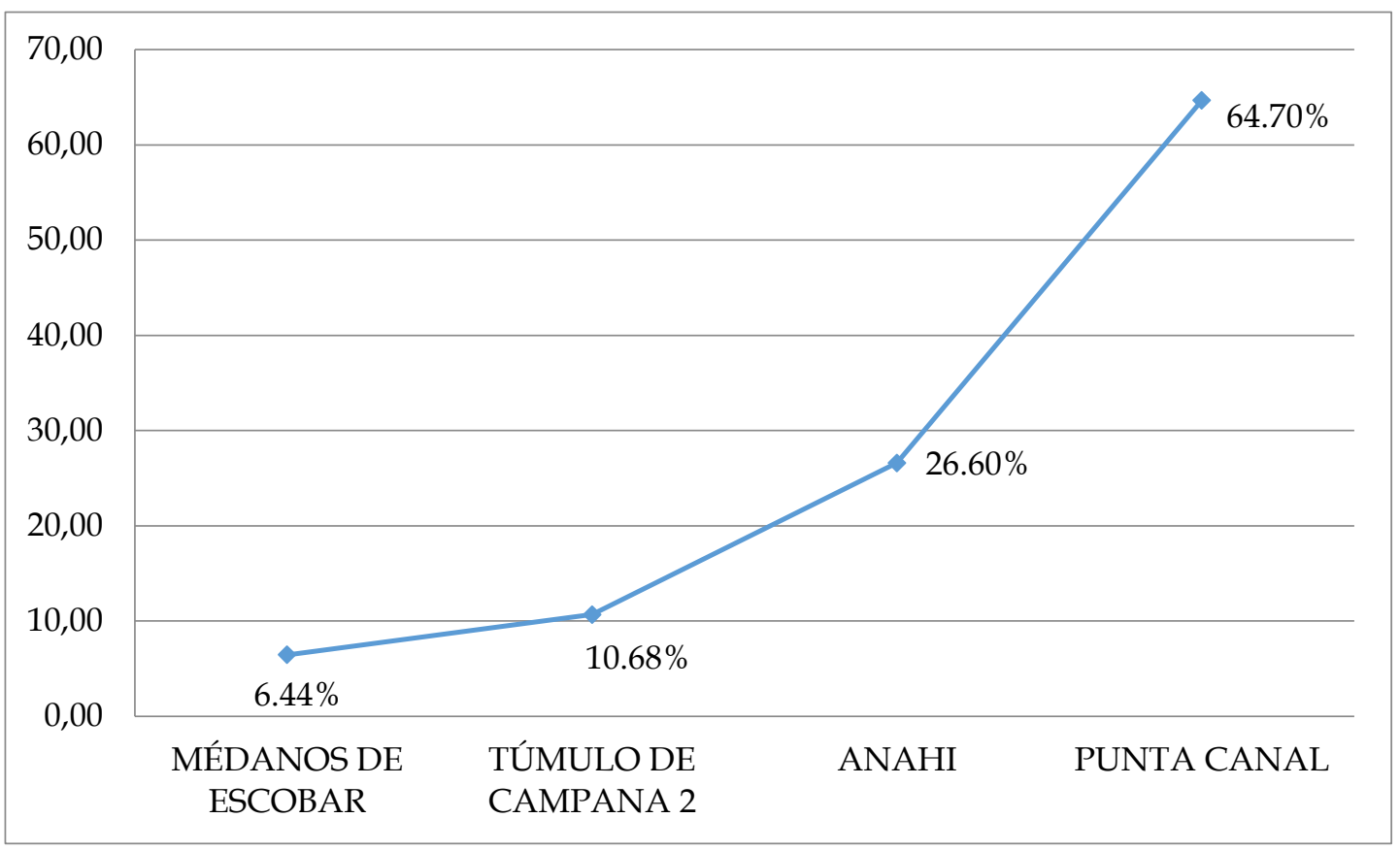

Figura 5. Representación de porcentaje del empleo de las técnicas de incisión y pintura asociadas en las distintas colecciones cerámicas analizadas.

\section{B- Unidades mínimas de diseño}

Estas unidades han sido definidas a partir de la identificación de figuras geométricas, tales como líneas horizontales, verticales, líneas zigzag, triángulos, líneas escalonadas, entre otras, y las combinaciones que componen los distintos diseños empleados en la decoración de la alfarería. Se han diferenciado aquellas que poseen una figura geométrica como simple y las que combinan variadas figuras como complejas. En algunos casos se han considerado las denominaciones empleadas históricamente en la bibliografía especializada sobre motivos estilísticos de la zona (Caggiano et al. 2001; Rodrigué 2005; González y Frère 2010), como por ejemplo los términos "banderitas", "campos rellenos" y "grecas".

En el sitio Médanos de Escobar, se ha observado que las líneas, en distintas variantes, alcanzan el $87 \%$ de las unidades de diseño elegidas para la decoración de las vasijas. Luego, se encuentran las unidades triangulares simples $(8 \%)$ y en menores proporciones las unidades triangulares y los campos rellenos ( $2 \%$ cada uno). El diseño de banderitas también aparece en bajos porcentaje y es en el único sitio donde es identificado (Figuras 8 y 9). Por otra parte, en el sitio Túmulo de Campana 2 se observa mayor variabilidad en las elecciones de los diseños, las líneas horizontales alcanzan un $41 \%$ y las verticales un $14 \%$. En segundo lugar, se observan altas proporciones de las figuras "rellenas" tales como los campos rellenos (35 \%) y los triángulos rellenos (4 \%). En bajas proporciones aparecen las figuras cerradas (2\%) (Figura 6 y 7 ). 

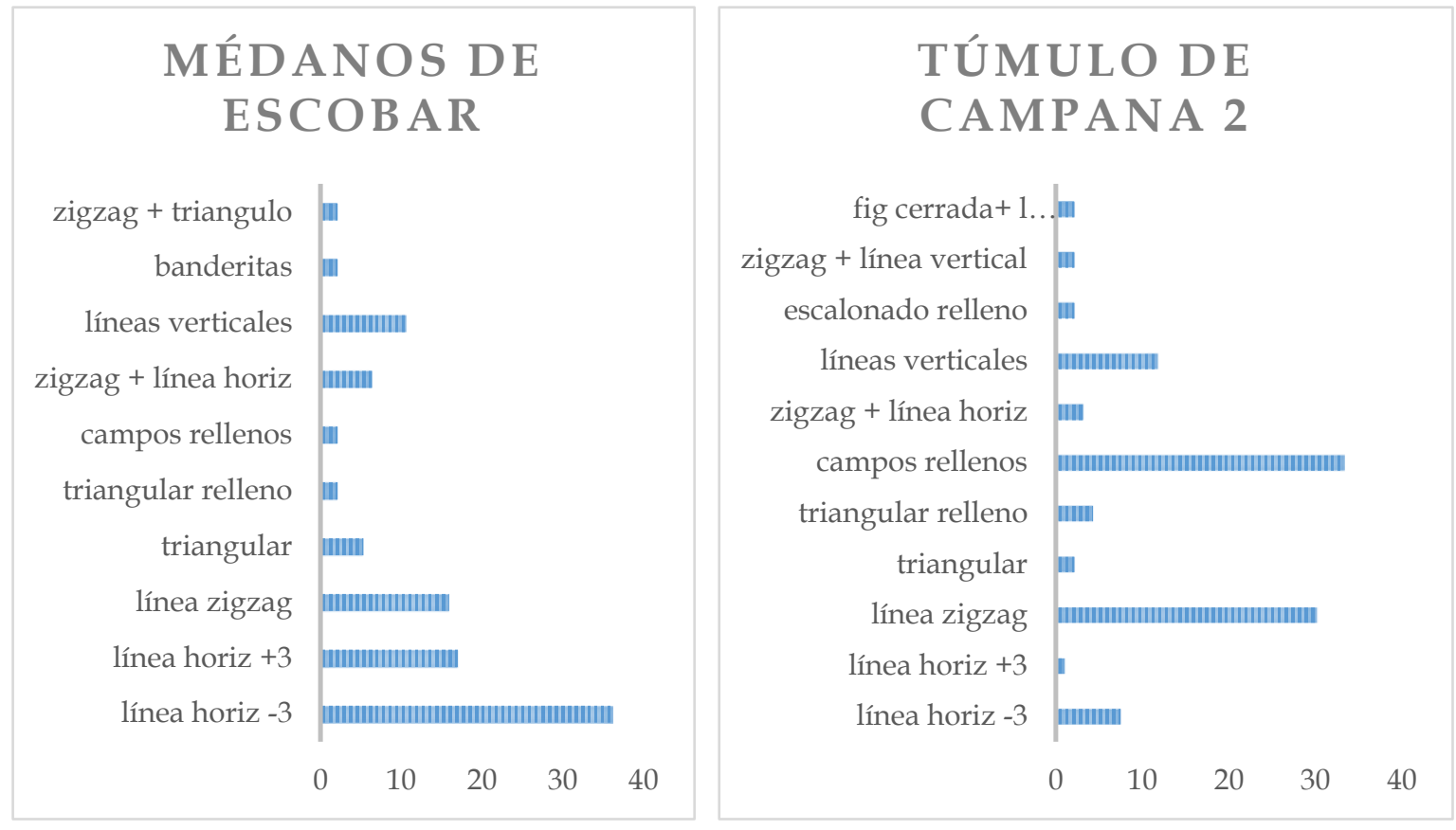

Figura 6. Izq. Unidades mínimas de diseño identificadas en la colección Médanos de Escobar (n =94). Der. Unidades mínimas de diseño identificadas en la colección de Túmulo de Campana 2 $(n=93)$.

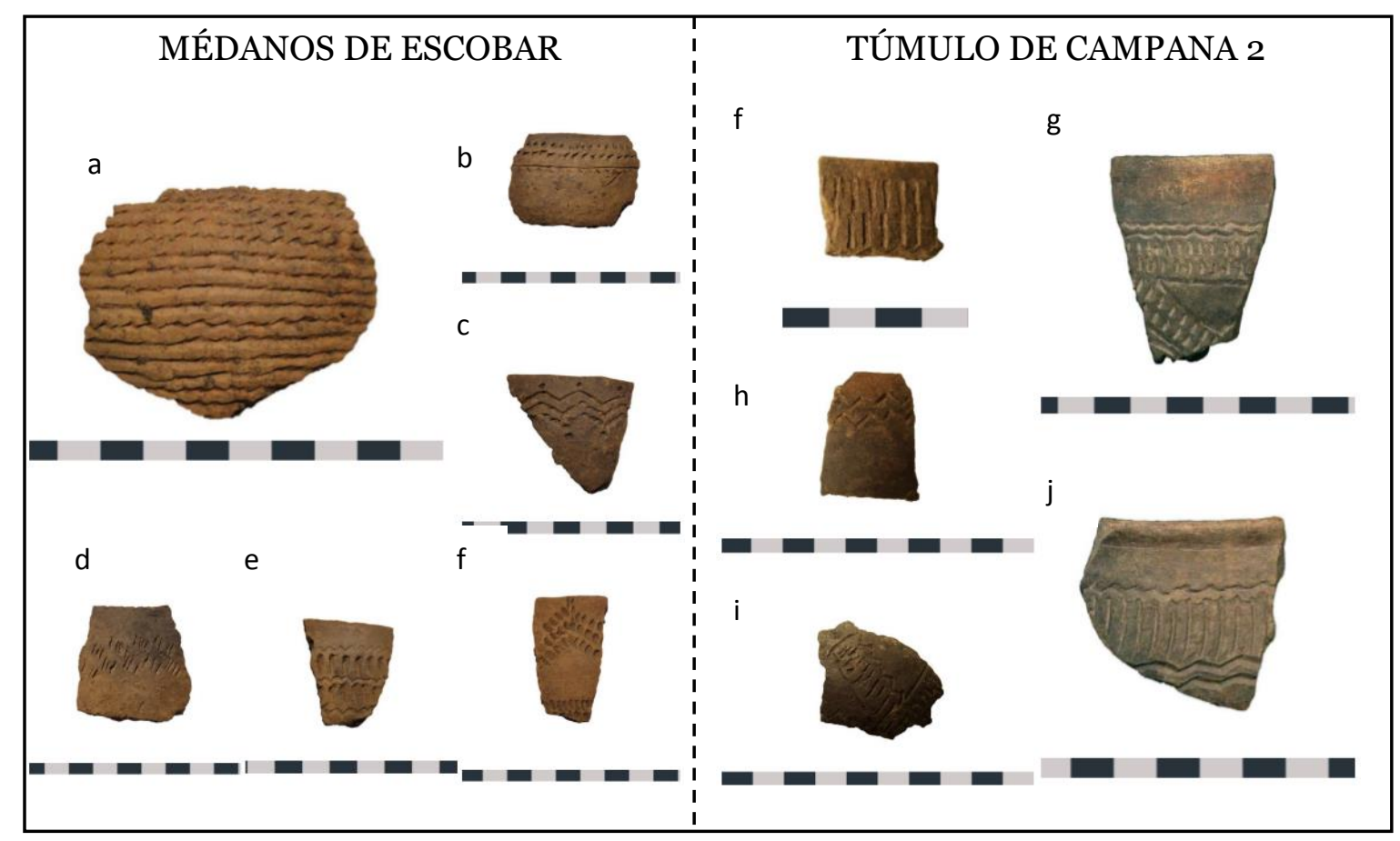

Figura 7. Izq. Tiestos cerámicos decorados del sitio Médanos de Escobar con líneas horizontales ( $a$; b), líneas en zigzag (c), banderitas (d), campos rellenos (e) y triangular

(f). Der. Tiestos cerámicos decorados procedentes del sitio Túmulo de Campana 2 líneas verticales (f), triangular relleno (g; i), zigzag (h) y campos rellenos (j). 
En el caso del sitio Anahí, las líneas siguen manteniendo una elevada representación (57 \%) siendo las líneas horizontales y en zigzag las más empleadas. En segundo lugar, aparecen los diseños denominados como grecas (18\%) y las figuras cerradas $(16 \%)$. En menores proporciones se observan los diseños triangulares simples (6 \%) y rellenos (2\%) (Figuras 8 y 9). Finalmente, en el sitio Punta Canal, el porcentaje de líneas es mayor que en el sitio Anahí y alcanza el 70\%. Luego se observan los diseños tales como figuras cerradas (14 \%) y grecas (7 \%) y en bajas proporciones aparecen los diseños triangulares simples (4\%) y los campos rellenos (3\%) (Figuras 8 y 9).

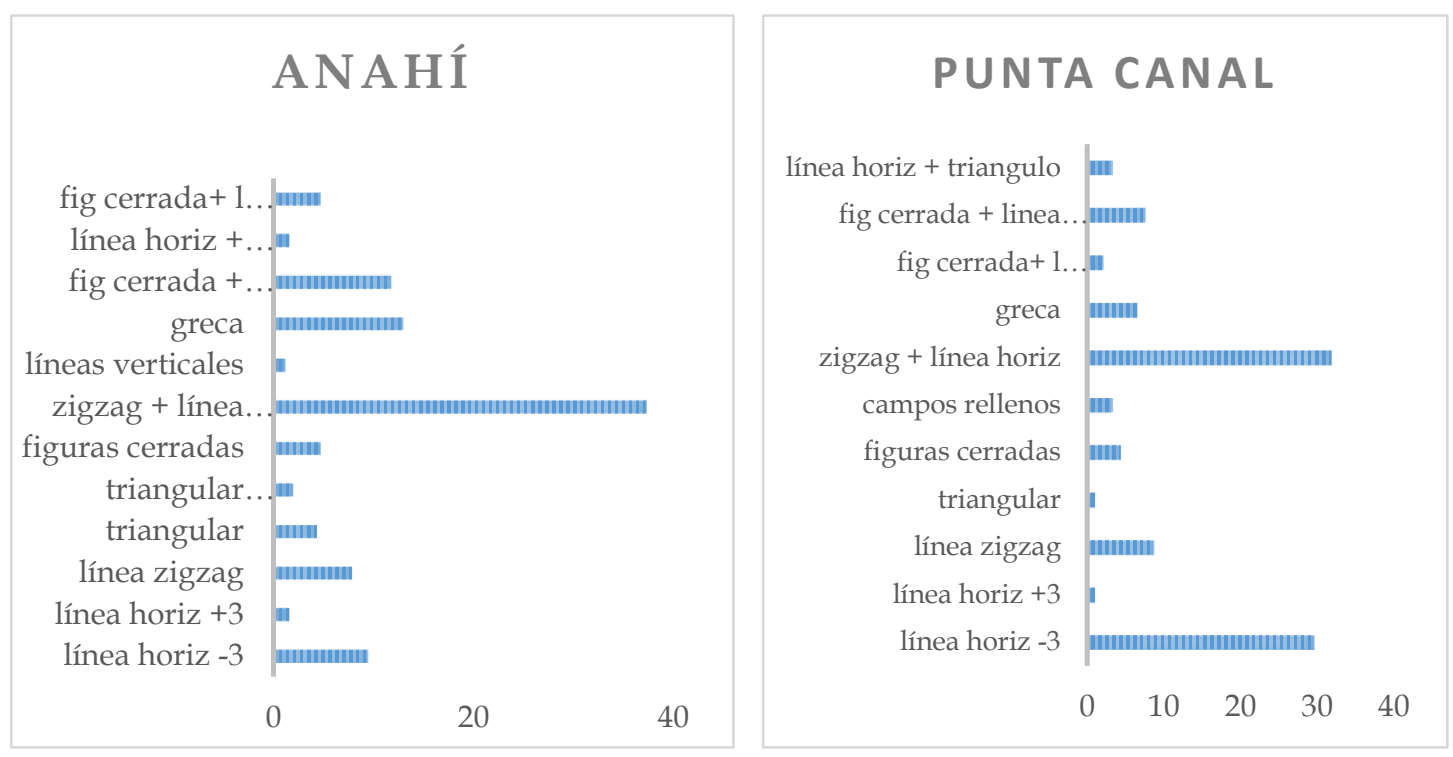

Figura 8. Izq. Unidades mínimas de diseño identificadas en la colección Anahí ( $\mathrm{n}=255)$. Der. Unidades mínimas de diseño identificadas en la colección Punta Canal ( $\mathrm{n}=91)$.

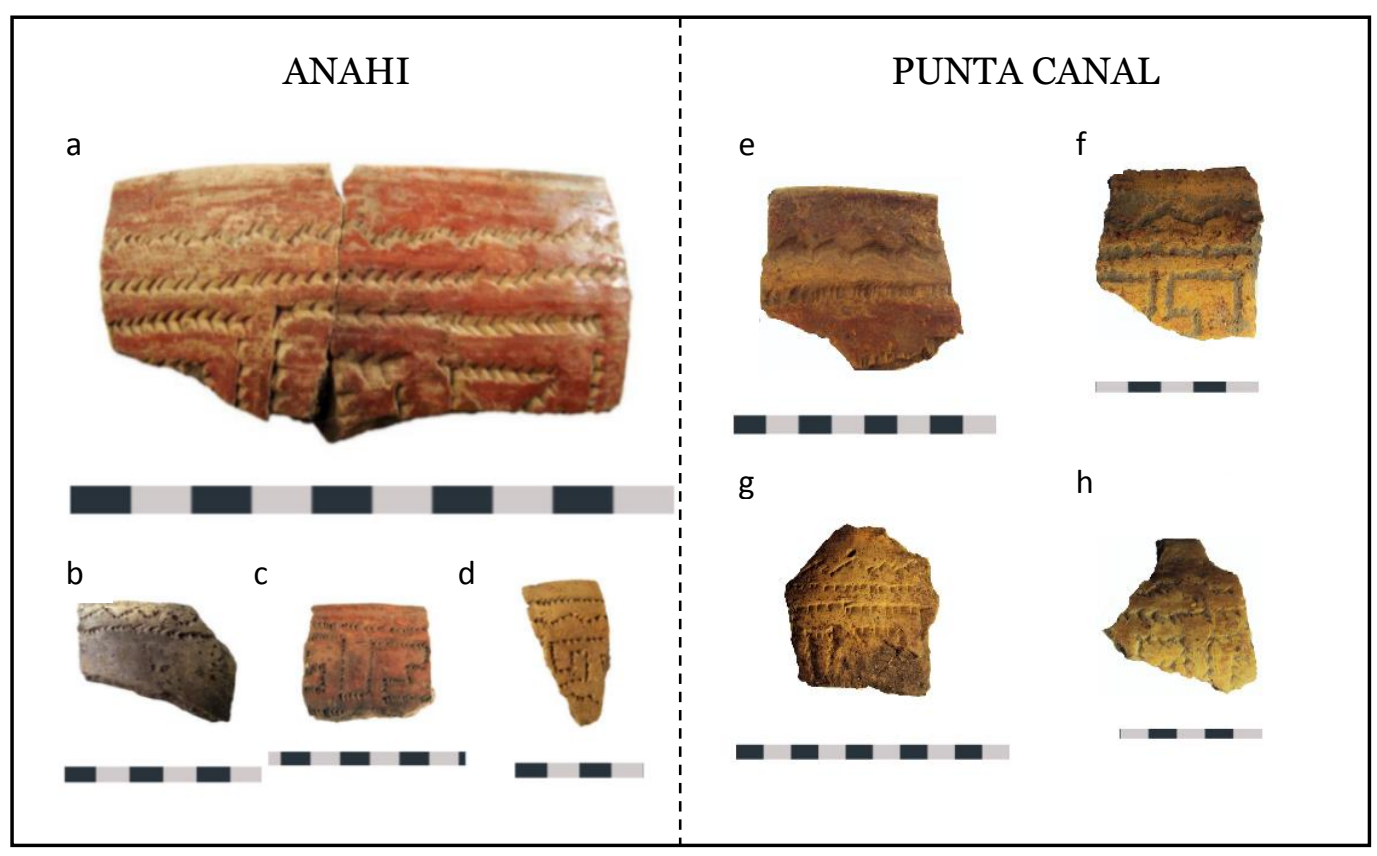

Figura 9. Izq. Tiestos cerámicos decorados del sitio Anahí con líneas horizontales y zig zag (b) y grecas (a; c; d). Der. Tiestos cerámicos decorados procedentes del sitio Punta Canal con líneas horizontales y zigzag (e) y grecas (f; $g$; h). 


\section{C- Motivos}

Finalmente, la relación entre las unidades mínimas de diseño identificadas y las técnicas de incisión empleadas para su ejecución es la que nos permite definir los motivos estilísticos presentes en los BRM. En algunos casos los mismos diseños (es decir, las mismas figuras geométricas) han sido realizados empleando distintas técnicas de incisión, por lo tanto, han sido analizados como motivos distintos. Esta situación se observa con los diseños de líneas horizontales y de triángulos; se ha observado la ejecución de estos diseños tanto con línea continua como con surco rítmico (Tabla 3).

\begin{tabular}{|c|c|c|c|}
\hline UNIDAD DE DISEÑO & $\begin{array}{l}\text { TECCNICA DE } \\
\text { INCISIÓN }\end{array}$ & MOTIVO & FIGURAS \\
\hline $\begin{array}{c}\text { LÍNEAS } \\
\text { HORIZONTALES }\end{array}$ & línea continua & 1 & \\
\hline $\begin{array}{c}\text { ÚNEAS } \\
\text { HORIZONTALES }\end{array}$ & surco rítmico & 2 & \\
\hline LÍNEAS VERTICALES & que brado & 3 & \begin{tabular}{|l|} 
IIIIIIIIIIIIIIII \\
IIIIIIIIIIIIIII \\
IIIIIIIIIIIIII
\end{tabular} \\
\hline TRIANGULAR & linea contimua & 4 & \\
\hline TRIANGULAR & surco rítmico & 5 & \\
\hline $\begin{array}{l}\text { TRIANGULAR } \\
\text { RELLENO }\end{array}$ & $\begin{array}{c}\text { línea continua } \\
\text { con punteado o } \\
\text { que brado }\end{array}$ & 6 & \\
\hline FIGURAS CERRADAS & surco rítmico & 7 & \\
\hline CAMPOS RELLENOS & $\begin{array}{l}\text { línea continua } \\
\text { con punteado o } \\
\text { que brado }\end{array}$ & 8 & 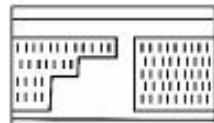 \\
\hline BANDERTIAS & quebrado & 9 & 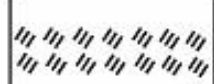 \\
\hline GRECAS & surco rítmico & 10 & 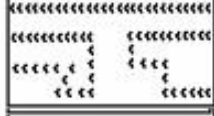 \\
\hline
\end{tabular}

Tabla 3. Motivos estilísticos identificados en las colecciones analizadas. 
Se destaca una mayor variabilidad de motivos en los sitios más antiguos, siendo Túmulo de Campana 2 el que mayor repertorio de motivos posee. En cambio, en los sitios pertenecientes al bloque temporal tardío se observa una menor diversidad y mayores correspondencias en las elecciones tomadas en ambos sitios (Tabla 4).

Las líneas horizontales son motivos simples que resultan recurrentes en todas las colecciones. Por otra parte, los motivos triangulares si bien aparecen en gran parte de ellos la forma de ejecución cambia $y$, por lo tanto, los motivos triangulares de Túmulo de Campana 2 son distintos a aquellos que aparecen en las colecciones de Anahí y Punta Canal. Esta situación se repite con los motivos complejos tales como los campos rellenos y las grecas, los primeros aparecen recurrentemente en Túmulo de Campana 2 y las segundas, con mayores proporciones en los sitios tardíos (Tabla 4).

\begin{tabular}{|c|c|c|c|c|}
\hline & $\begin{array}{c}\text { MÉDANOS DE } \\
\text { ESCOBAR }\end{array}$ & $\begin{array}{l}\text { TÚMULO DE } \\
\text { CAMPANA } 2\end{array}$ & ANAHÍ & $\begin{array}{l}\text { PUNTA } \\
\text { CANAL }\end{array}$ \\
\hline MOTIVO 1 & $\mathbf{X}$ & $\mathbf{X}$ & $\mathbf{X}$ & $\mathbf{X}$ \\
\hline MOTIVO 2 & $\mathbf{X}$ & $\mathbf{X}$ & $\mathbf{X}$ & $\mathbf{X}$ \\
\hline MOTIVO 3 & - & $\mathbf{X}$ & - & - \\
\hline MOTIVO 4 & - & - & $\mathrm{X}$ & $X$ \\
\hline MOTIVO 5 & - & $X$ & - & - \\
\hline MOTIVO 6 & - & - & $X$ & 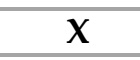 \\
\hline MOTIVO 7 & $\mathrm{X}$ & $\mathrm{X}$ & - & - \\
\hline MOTIVO 8 & - & $X$ & - & - \\
\hline MOTIVO 9 & $\mathrm{X}$ & - & - & - \\
\hline MOTIVO 10 & - & - & $\mathbf{X}$ & $\mathbf{X}$ \\
\hline
\end{tabular}

Tabla 4. Motivos estilísticos presentes en cada una de las colecciones analizadas.

\section{Discusión}

La cuenca inferior del río Paraná ha sido habitada por grupos cazadores recolectores complejos desde hace por lo menos 2500 años ${ }^{14} \mathrm{C}$ AP (Loponte y Acosta 2003; Loponte et al. 2012). En el sector de los BRM se plantea un modelo de aumento demográfico con un pico alrededor de 1100 años AP que aceleró un proceso de complejización social e intensificación económica que se evidencia con cambios en la explotación y manipulación del ambiente. Junto con la estabilidad territorial y cierto grado de circunscripción espacial que reflejan las ocupaciones de estos grupos, el aumento en la población también derivó en un aumento por la competencia y defensa activa de los espacios más productivos (Loponte 2008; Mazza y Loponte 2012). En este contexto, se plantea que los límites sociales entre los grupos cazadores recolectores de la zona tuvieron una marcación cultural más estricta materializada, entre otros aspectos, en el estilo cerámico y, posiblemente, también territoriales con las poblaciones adyacentes dentro de la región. 
Las técnicas decorativas y las representaciones iconográficas presentes en la alfarería pudieron actuar como una vía material para expresar el establecimiento de estos límites a lo largo del tiempo. La alfarería, al igual que otras tecnologías, materializa una visión del mundo particular que se conforma por el significado que cada comunidad construye sobre el mundo que los rodea. En este sentido, Kohring (2012: 108) sostiene: "Thus, how we view the world and make sense of it is channelled through our body not only from a material engagement aspect as implicated in the approaches above, but also through our 'communities of practice' (per Wenger 1998)". Estas comunidades de práctica brindan un marco para aprender técnicas específicas sobre la forma de hacer y entender el mundo. Dichas técnicas se basan en la repetición de actividades que se refuerzan a través de la interacción continua con la comunidad (Kohring 2012).

Las elecciones tomadas por los/as artesanos/as en el pasado responden a presiones tanto materiales como simbólicas y son resultado de procesos de aprendizaje asimilados en tradiciones que se encuentran vinculadas con la identidad social (Gosselain 1998). La alfarería de la zona de estudio ha reflejado una gran homogeneidad en las elecciones vinculadas a las técnicas de manufactura (Pérez 2010), sin embargo, las técnicas decorativas e iconográficas de las vasijas muestran mayor variabilidad (Rodrigué 2005; Loponte 2008). En este sentido, Gosselain (2000) plantea que los aspectos decorativos son altamente maleables y pueden ser transmitidos después del proceso de aprendizaje, por lo tanto, reflejarían facetas de la identidad más situacionales o temporarias. Por el contrario, la etapa de modelado de la pieza (o "primary forming" - Rye 1981), demuestra ser más resistente al cambio y se relaciona con el proceso de aprendizaje primario. Entonces, siguiendo a dicho autor, las técnicas de manufactura compartidas entre las poblaciones de los BRM reflejan un proceso de aprendizaje compartido y, por lo tanto, la conformación de una misma "comunidad de práctica", en el sentido de Kohring (2012). La variabilidad presente en el estilo decorativo de las vasijas se relaciona con la conformación de una identidad situacional o temporaria, en este caso, vinculada con un contexto de mayor competencia por los recursos y mayor fragmentación social. Se plantea entonces, que dichos rasgos han sido empleados de forma intencional para reafirmar, negociar y reproducir una identidad social que demarca límites sociales más estrictos en el interior de esta comunidad a partir de los 1100 años AP.

En este trabajo se ha observado que las colecciones que pertenecen al bloque temporal temprano presentan una elevada variabilidad en las técnicas decorativas y en los motivos estilísticos, tanto de forma intra e intersitio. Por lo tanto, en este período los sitios de Médanos de Escobar y Túmulo de Campana 2 reflejan porcentajes altos de decoración, pero con bajos niveles de estandarización y un criterio flexible sobre la estética visual de la alfarería. En cambio, en las colecciones que pertenecen al bloque temporal tardío se observa una menor variabilidad en las técnicas decorativas y mayor correspondencia en los motivos estilísticos presentes en las vasijas. Se plantea, entonces, que la aparición de un estilo decorativo homogéneo y distinguible refleja el 
establecimiento de límites sociales más estrictos en relación con otros grupos de región. Los resultados obtenidos y expuestos en este trabajo permiten apoyar la hipótesis principal que plantea que en caso de que actúe la transmisión conformista se espera encontrar menor variabilidad en el bloque temporal tardío, con una mayor estandarización en las técnicas decorativas y la presencia de motivos complejos diferenciables entre distintas unidades arqueológicas del área del humedal del Paraná inferior. A partir del marco teórico evolutivo se plantea que en el caso del bloque temporal temprano el estilo presente en las técnicas decorativas y las representaciones iconográficas estaría actuando de manera neutral. Posteriormente, comenzaría un proceso de selección y una forma de transmisión repetitiva de estos rasgos hacia el interior de la comunidad. Se propone que este cambio en la forma de transmisión a través del tiempo se corresponde con el establecimiento de límites sociales más estrictos y la necesidad de emplear la cerámica como un soporte material para reflejar una identidad. Dentro de un contexto de mayor competencia por los recursos y mayor fragmentación social, la definición de una identidad grupal debió haber sido un proceso dinámico de construcción y deconstrucción hacia el interior y exterior de estos grupos.

Tomando en consideración la microzona de los BRM, Loponte et al. (2012) reconocieron la presencia de dos grandes linajes que se solapaban en tiempo y en espacio. En este trabajo hemos analizado la trayectoria a través del tiempo de colecciones cerámicas que coinciden con las características propuestas para el "linaje 1". Las colecciones cerámicas del "linaje 2" se caracterizan por poseer conjuntos enteramente lisos o con un porcentaje muy pequeño de bordes decorados, siendo esta decoración muy irregular y basada en líneas horizontales y líneas en zigzag. En este sentido, se pueden comparar los resultados obtenidos para los sitios Anahí y Punta Canal con otros contemporáneos como Garín, Guazunambí, Las Vizcacheras, La Bellaca 1 y La Bellaca 2 (Loponte 2008)2. En el primer caso, el análisis preliminar de 1200 fragmentos cerámicos refleja altas proporciones de decoración con la técnica de incisión de surco rítmico, motivos de grecas (Loponte 2008; Pérez et al. 2012). En este conjunto también se observa una elevada asociación entre la incisión y la pintura en los mismos tiestos y la presencia de pintura en color rojo (Loponte 2008). Por esta razón la cerámica de este sitio puede ser integrada con aquellas de Anahí y Punta Canal, con las cuales comparte las mismas elecciones tecnoestilísticas. Por otra parte, los sitios restantes han sido identificados como pertenecientes al linaje 2. Los escasos fragmentos decorados reflejan en Las Vizcacheras un "manejo anárquico del campo decorativo"(Loponte 2008: 175) y la presencia de tiestos pintados con pigmentos de color rojo y negro (Loponte 2008). Por otra parte, Guazunambí presenta sólo un 3,6\% de bordes con decoración incisa $(n=26)$ y la técnica empleada en forma mayoritaria es la línea continua, que en muchos casos aparecen como trazos simples o aislados (Loponte 2008). La presencia de pintura de color rojiza se observó sobre las bases de pequeños recipientes y de color blanquecino en alfarerías tubulares (Loponte 2008; Pérez y Cañardo 2004). En el caso de La Bellaca sitio 1, la presencia de tiestos con decoración es muy baja tanto con la técnica de incisión (1 \% del total de tiestos) como 
de pintura (0,8 \% del total de tiestos). Por último, en el sitio La Bellaca sitio 2 si bien la proporción de bordes decorados con incisión asciende ligeramente a 1,4\%, se ha observado que los tiestos decorados presentan una pasta diferente a las del conjunto del sitio, siendo similar en cuanto a técnica decorativa a la alfarería de sitios ubicados en el sur de Entre Ríos, tales como el sitio La Argentina (Loponte, 2008; Pérez et al. 2012). Este tipo de iconografía es común en el curso medio e inferior del río Uruguay y el Paraná inferior (Caggiano et al. 2001). Entonces, el análisis estilístico de la alfarería en los BRM a partir de los 1100 años 14C AP refleja, por un lado, un conjunto de sitios con presencia de un estilo decorativo homogéneo y distintivo y, por otro lado, un conjunto de sitios con una baja decoración en la cerámica y la presencia de motivos simples como líneas horizontales o en zigzag, con excepción del sitio La Bellaca 2.

En una escala regional más amplia, los diseños de la alfarería presentes en la cuenca inferior del río Paraná han sido identificados en zonas adyacentes como la cuenca media del Paraná y la Depresión del Salado que reflejarían redes de interacción e intercambio entre diferentes grupos (Rodrigué 2005; González y Frère 2009; Di Prado 2018). Los diseños descritos como líneas horizontales, líneas en zigzag y banderitas forman parte un repertorio que conforma un código semiótico compartido entre poblaciones cazadoras-recolectoras (Rodrigué 2005). Sin embargo, pueden mencionarse características particulares y distintivas en ambas zonas. En la cuenca media del Paraná se ha registrado una mayor presencia de la unidad arqueológica denominada GoyaMalabrigo (Loponte y Acosta 2016; Ottalagano 2015; Ottalagano 2016; Politis y Bonomo 2012; Ceruti 2003), que si bien posee elementos en común con las poblaciones de la cuenca inferior del río Paraná, la decoración en la alfarería presenta características particulares. Entre ellas, se ha observado la realización de incisión a través del surco rítmico con estampado de intermediarios más grandes, incisiones con surco rítmico sobre los labios, el empleo de cordeles y la decoración por pastillaje (Loponte y Acosta 2016). Las vinculaciones entre esta unidad con el sitio 1 de Túmulo de Campana fue postulada por Politis y Bonomo (2012), pero su reexcavación demostró su vinculación con el linaje 1, siendo los pocos modelados zoomorfos recuperados probablemente producto de los complejos procesos de movilidad e intercambio de los grupos humanos de la región (Loponte y Acosta 2015, 2017). Por otra parte, la zona de la Depresión del Salado presenta una alfarería incisa en donde se reconocen diseños iconográficos similares. Se ha mencionado la presencia de motivos simples como las líneas (rectas, onduladas y en zigzag), puntos y figuras de triángulos y motivos complejos como guardas formadas por una combinación de elementos como líneas y puntos, rectángulos, líneas, escalonados y líneas, cruciformes (González y Frère 2009; González y Frère 2010; Frère 2015).

En este sentido, se plantea que en los BRM a partir de los 1100 años AP se han seleccionado diseños iconográficos que también están presentes en otras áreas adyacentes y que han permitido conformar un estilo decorativo homogéneo y distintivo que lo diferencia con la alfarería de otros conjuntos que habitaban este mismo espacio de forma contemporánea. Además de la iconografía, las técnicas 
decorativas reflejan una mayor estandarización tanto en relación a las técnicas de incisión como a la presencia de pintura en asociación con los diseños incisos que refleja una mayor normatividad hacia el interior de las prácticas alfareras de estos grupos.

\section{Conclusiones}

Este trabajo ha buscado explorar las formas de transmisión de rasgos identitarios dentro de los cazadores recolectores que habitaron los BRM a través de un análisis estilístico de la alfarería. Tomando el modelo de aumento demográfico planteado para la zona hace 1100 años ${ }^{14} \mathrm{C}$ AP, nos preguntamos cómo esto podría estar reflejado en el registro arqueológico. El análisis de cuatro conjuntos cerámicos, dos de ellos más tempranos, ha demostrado sustanciales diferencias en el bloque cronológico previo respecto a los dos más recientes, siendo congruentes con la generación de cambios en relación con la competencia por el ambiente. Si bien, existen continuidades entre los conjuntos que permite integrarlos dentro de una "comunidad de práctica" (Kohring 2012), las diferencias observadas tienen un claro vector cronológico. De esta manera, el estilo de la cerámica permite integrarse al análisis de la variabilidad espacio-temporal observada entre los distintos linajes arqueológicos de la región, como así también en relación con la variabilidad interna de cada uno de ellos, junto con los análisis de otros rasgos del registro arqueológico.

Agradecimientos: Este trabajo es resultado de la investigación desarrollada durante mi tesis de Licenciatura. Agradezco especialmente por su apoyo y comentarios a Daniel Loponte, Alejandro Acosta y Maricel Pérez, y a todo el equipo del humedal por el trabajo en conjunto. A los/as evaluadores que con sus comentarios y sugerencia han enriquecido el contenido de este trabajo. Los conceptos vertidos aquí son de exclusiva responsabilidad de la autora.

\section{Notas}

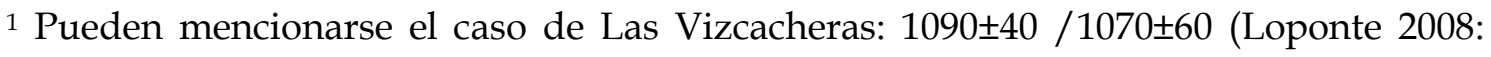
174) o El Cazador 3: 1091 \pm 43 / $1063 \pm 46$ / 1031 \pm 36 /921 \pm 43 (Acosta et al. 2015: 311).

${ }^{2}$ Fechados radiocarbónicos de cada sitio: Garín $1060 \pm 60$ años ${ }^{14} \mathrm{C}$ AP (Loponte 2008:241), Guazunambí $940 \pm 60$ años ${ }^{14} \mathrm{C}$ AP (Loponte 2008: 286), Las Vizcacheras 1090 \pm 40 años ${ }^{14} \mathrm{C}$ AP y $1070 \pm 60$ años ${ }^{14} \mathrm{C}$ AP (Loponte 2008: 174), La Bellaca $11110 \pm 70$ años ${ }^{14} \mathrm{C}$ AP (Loponte 2008: 193) y La Bellaca $2680 \pm 80$ años ${ }^{14} \mathrm{C}$ AP (Loponte 2008: 212).

\section{Bibliografía citada}

Acosta, A., D. Loponte y L. Mucciolo

2010 Comparando estrategias de explotación faunística en el humedal del Paraná inferior: cazadores-recolectores versus horticultores amazónicos. Zooarqueología a principios del Siglo XX: aportes teóricos, metodológicos y casos de estudio, (ed. por M. 
Gutiérrez, M. de Nigris, P. M. Fernández, M. Giardina, A. Gil, A. Izeta, G. Neme y H, Yacobaccio), pp. 177-188. Libros del Espinillo, Ayacucho.

Acosta, A., D. Loponte y P. Tchilinguirian

2013 Nuevos aportes para la arqueología del humedal del Paraná inferior: el sitio Médanos de Escobar. Relaciones-Sociedad Argentina de Antropología 38(1): 19-35.

Acosta, A. y L. Pafundi

2005 Zooarqueología y Tafonomía de Cavia aperea en el humedal del Paraná inferior. Intersecciones en Antropología 6: 59-74.

Acosta, A, N. Buc y N. Davrieux

2015 Producción y uso de ornamentos en las tierras bajas de Sudamérica: el caso de las poblaciones humanas prehispánicas del extremo meridional de la cuenca del Plata (Argentina). MUNIBE Antropologia-Arkeologia 66: 309-325.

Adroher Auroux, A. M., C. Carreras Monfort, R. D. Almeida, A. Fernández Fernández, J. Molina Vidal y C. Viegas

2016 Registro para la cuantificación de cerámica arqueológica: estado de la cuestión y una nueva propuesta. Protocolo de Sevilla (PRCS/14). Zephyrus. Revista de Prehistoria y Arqueología 78: 87-110.

Aldazábal, $\mathrm{V}$.

2002 La ocupación humana en el sector centro oriental de la Pampa Deprimida, provincia de Buenos Aires, Argentina. Tesis doctoral. Facultad de Filosofía y Letras. Universidad de Buenos Aires. Buenos Aires.

2008 Entre líneas y puntos. Interpretando aspectos del diseño de la cerámica del sector centro-oriental de la Pampa deprimida, provincia de Buenos Aires, Argentina. Relaciones de la Sociedad Argentina de Antropología XXXIII: 61-84.

Ali, S.

2016 Los límites sociales en los cazadores-recolectores del humedal del Paraná inferior. Un análisis de la decoración y el estilo en la alfarería. Tesis de licenciatura. Facultad de Filosofía y Letras. Universidad de Buenos Aires. Buenos Aires.

Ali, S., M. Pérez, P. Bozzano y S. Domínguez

2020 Pigmentos en la cerámica del humedal del Paraná inferior: análisis físicoquímico MEB-EDX. Boletín del Museo de chileno de Arte Precolombino 25(1):171-182.

Ameghino, F.

1947 [1880] La Antigüedad del Hombre en el Plata. Editorial La Cultura Argentina, Buenos Aires, Argentina.

Arrizurieta, P., N. Buc, B. Mazza, L. Mucciolo, J. Musali, F. Parisi, D. Pau y M. Pérez 2010 Nuevos aportes a la arqueología del sector continental del humedal del Paraná inferior. Arqueología Argentina en el Bicentenario de la Revolución de Mayo. XVII Congreso Nacional de Arqueología Argentina, Tomo V, (ed. por J. R. Bárcena y H. Chiavazza), pp. 1793-1797. Facultad de Filosofía y Letras, Universidad Nacional de Cuyo e INCIHUSACONICET, Mendoza 
Barth, F.

1976 Los grupos étnicos y sus fronteras. Fondo de cultura económica. México.

Binford, L. R.

1965 Archaeological systematics and the study of culture process. American Antiquity 31: 203-210.

Buc, $N$.

2019 Stylistic variability in bone tools from the Low Paraná wetland. Late Holocene, Argentina. Journal of Anthropological Archaeology 56: 101-112.

Caggiano, M. A.

1984 Prehistoria del NE. Argentino y sus vinculaciones con la República oriental del Uruguay y Sur de Brasil. Pesquisas, Antropología 38: 5-109.

Caggiano, M. A., V. H. Garay y C. Moreyra

2001 Iconografía bonaerense. Alfarería prehispánica. Ed. Hombre Barro Fuego. La Plata.

Capdepont, I. y M. Bonomo

2013 Análisis petrográfico del material cerámico del Delta del Paraná. Anales de Arqueología y Etnología 65-66: 127-147.

Ceruti, C.

2003 Entidades culturales presentes en la cuenca del Paraná Medio (margen entrerriana). Mundo de antes 3: 111-135.

Dietler, M. y I. Herbich

1998 Habitus, techniques, style: an integrated approach to the social understanding of material culture and boundaries. The archaeology of social boundaries (ed. por M. T. Stark), pp. 232-263. Smithsonian Institution Press. Washington DC.

Di Prado, V.S.

2018 Prácticas alfareras prehispánicas y procesos de interacción social en el centroeste de Argentina durante el Holoceno tardío. Latin American Antiquity 29 (3): 552-71.

Dunnell, R. C.

1978 Style and function: a fundamental dichotomy. American Antiquity 43: 192-202.

1989 Aspects of the application of evolutionary theory in archaeology. Archaeological thought in America (ed. por C. C. Lamberg-Karlovsky), pp. 35-49. Cambridge University Press. Cambridge.

Fernández de Oviedo y Váldez, G.

1944/1946 Historia General y Natural de las Indas, Islas y Tierra-Firme del Mar Oceáno. Editorial Guarania, Asunción del Paraguay.

Frére, M. M.

2015 Tecnología cerámica de los cazadores-recolectores-pescadores de la microrregión del río Salado, provincia de Buenos Aires. Tesis doctoral. Facultad de Filosofía y Letras. Universidad de Buenos Aires, Argentina

Frère, M. M., M. I. González, C. Di Lello, G. Polla, E. Freire, E. B. Halac, M. Reinoso, G. Custo y M. Ortiz

2016 Empleo de colorantes en coberturas de fragmentos de alfarería del río Salado bonaerense. Intersecciones en antropología 17: 45-55. 
González, M. I., y Frère, M. M.

2009 Talares y paisaje fluvial bonaerense: arqueología del río Salado. Intersecciones en antropología 10(2): 249-265.

González, M. I. y Frère, M. M.

2010 Diseños prehispánicos de la Alfarería Pampeana. Editorial de la Facultad de Filosofía y Letras, Buenos Aires.

Gosselain, O. P.

1998 Social and Technical Identity in a Clay Crystal Ball. Social Boundaries on the Sepik Coast of New Guinea (ed. por M. Stark), pp. 78-106. Smithsonian.

2000 Materializing identities: an African perspective. Journal of Archaeological Method and Theory 7(3): 187-217

Kohler, T., S. VanBuskirk y S. Ruscavage-Barz

2004 Vessels and villages: evidence for conformist transmission in early village aggregations on the Pajarito Plateau, New Mexico. Journal of Anthropological Archaeology 23: $100-118$.

Kohring, S.

2012 Conceptual knowledge as technologically materialised: a case study of pottery production, consumption and community practice. Embodied Knowledge. Perspectives on Belief and Technology (ed. por Stig Sørensen, MJ y Rebay-Salisbury, K.). Oxbow Books. Oxford, 106-117.

Kusch, M. F.

1991 Forma, diseño y figuración en la cerámica pintada y grabada de La Aguada. El arte rupestre en la arqueología contemporánea (ed. por M. Podestá, M. I. Hernández-Llosas y S. Renard), pp. 14-24. FECIC, Buenos Aires.

Kusch, M. F. y D. Conlazo

1984 Yacimiento Ezeiza: Análisis del tipo de ornamentación que caracteriza a la muestra de fragmentos decorados obtenidos en el mismo. ADEHA $V:$ 6-16.

Lechtman. H.

1977 Style in technology- Some early thoughts. Material Culture: Style, Organization, and Dynamics of Technology (ed. por H. Lechtman y R. Merril), pp. 3-20. West Publishing, Nueva York.

Lemmonier, $\mathrm{P}$.

1986 The study of material culture today: toward an anthropology of technical systems. Journal of anthropological archaeology 5(2): 147-186.

Loponte, D.

2008 Arqueología del Humedal del Paraná inferior (Bajíos Ribereños Meridionales). Tesis para optar por el título de Doctor en Ciencias Naturales. Facultad de Ciencias Naturales y Museo. Universidad Nacional de La Plata. Buenos Aires.

2020 La agricultura prehispánica en el nordeste argentino analizada a través de los isótopos estables. Anuario de Arqueología 12(12): 25-64.

Loponte, D. y A. Acosta

2003 Arqueología de cazadores-recolectores del sector centro-oriental de la región pampeana. Runa. Archivo para las ciencias del hombre 24: 173-212. 
2015 Los sitios arqueológicos Túmulo de Campana 1 y 2 dentro del contexto regional del humedal del Paraná inferior. Revista de Antropología del Museo de Entre Ríos 1(2): 11-40.

2016 Los contextos Goya-Malabrigo del noreste argentino. Revista Cadernos do Ceom 29(45): 125-187.

2017 Túmulo de Campana sitio 1 (Zeballos y Pico, 1878). Nuevos y viejos datos para su estudio. Revista de Antropología del Museo de Entre Ríos 3 (1): 40-92.

Loponte, D., A. Acosta y J. Musali

2004 Complejidad social: cazadores-recolectores y horticultores en la región pampeana. Aproximaciones Arqueológicas Pampeanas. Teorías, Métodos y Casos de Aplicación Contemporáneos (ed. por G. Martínez, M. A. Gutiérrez, R. Curtoni, M. Berón y P. Madrid), pp. 41- 60. Facultad de Ciencias Sociales, UNCPBA.

Loponte, D., A. Acosta y L. Mucciolo.

2012 Contribución a la arqueología del delta del Paraná. El nivel acerámico del sitio Isla Lechiguanas I. Comechingonia. Revista de Arqueología 16 (1): 229-268.

Loponte, D., F. Ottalagano, M. Pérez, L. Malec, C. Ramos, P. Bozzano, M. Iribarren, R. Pérez, G. Leiva, S. Domínguez, S. Ali \& A. Acosta

2019a Mortuary Pottery and Sacred Landscapes in Complex Hunter-gatherers in the Paraná Basin, South America. Cambridge Archaeological Journal 30(1): 1-23.

Loponte, D., J. Morales, A. Gogichaishvili, y A. Acosta

2019b Caracterização química da cerâmica arqueológica do Baixo Rio Paraná. Cerâmica 65(374): 319-326.

Lothrop, S.

1932 Indians of the Paraná Delta River. Annals of the New York Academy of Sciences 33: $77-232$.

Malvárez, A. I.

1999 El delta del río Paraná como mosaico de humedales. Tópicos sobre Humedales Subtropicales y Templados de Sudamérica (ed. por A. Malvárez y P. Kandus ), pp. 35-54. Universidad de Buenos Aires, Buenos Aires.

Mazza, B.

2019 Entheseal changes among late Holocene hunter-gatherers from the southern extreme of La Plata basin (Argentina). Archaeological and Anthropological Sciences 11(5): 1865-1885.

Mazza, B. y D. Loponte

2012 Las prácticas mortuorias en el humedal del Paraná inferior. Arqueología Iberoamericana 13: 3-21.

Neiman, F.

1995 Stylistic Variation in Evolutionary Perspective: Inferences from Decorative Diversity and Interassemblage Distance in Illinois Woodland Ceramic Assemblages. American Antiquity 60 (1): 7-36.

Naranjo, G., L. Malec y M. Pérez

2010 Análisis de ácidos grasos en alfarería arqueológica del humedal del Paraná inferior. Avances en el conocimiento de su uso. Trabajo presentado en el XVII Congreso Nacional de Arqueología Argentina, Vol. 4, pp. 1493-1498. Facultad de Filosofía y Letras de la Universidad Nacional de Cuyo, Mendoza. 
Orton, C., P. Tyers, P. y A. Vince

1997 La cerámica en arqueología. Crítica. Barcelona

Ottalagano, F. V.

2015 Explorando la variabilidad petrográfica entre vasijas decoradas y lisas del sitio La Palmera 2 (Entre Ríos, Argentina): hacia un abordaje microscópico del arte cerámico prehispánico de la cuenca del río Paraná. Revista Chilena de Antropología 20 (2): 57-68.

2016 A diachronic study of pre-Hispanic vessels from the middle basin of Paraná River (South America) using a petrographic approach. Journal of Archaeological Science: Reports 9: 320-329.

Ottalagano, F. V. y M. Pérez

2013 Estudios petrográficos comparativos: un acercamiento regional a la tecnología cerámica del Delta del Paraná. Cuadernos del Instituto Nacional de Antropología y Pensamiento Latinoamericano, Series Especiales 1 (2): 79-94.

Ottalagano, F. V., S. A. Domínguez y P. B. Bozzano

2015 Arqueología de los colores: análisis MEB-EDX de mezclas pigmentarias en cerámicas prehispánicas de la cuenca del río Paraná (Provincia de Entre Ríos, Nordeste de Argentina). Boletín del Museo Chileno de Arte Precolombino 20(2): 57-68.

Pérez, M.

2010 Tecnología de producción de la alfarería durante el Holoceno tardío en el humedal del Paraná inferior. Un estudio petrográfico. Tesis inédita de para optar por título de Licenciatura en Arqueología, Facultad de Filosofía y Letras. Universidad de Buenos Aires. Buenos Aires.

Pérez, M. y L. Cañardo

2004 La producción y uso de la cerámica en el Norte de la Provincia de Buenos Aires. Aproximaciones Contemporáneas a la Arqueología Pampeana. Perspectivas teóricas, Metodológicas, Analíticas y Casos de Estudio (ed. por G. Martínez, M. A. Gutiérrez, R. Curtoni, M. Berón y P. Madrid), pp. 335-347. Olavarría, Facultad de Ciencias Sociales, UNCPBA.

Pérez, M. y T. Montenegro

2009 Análisis petrográfico del norte de la provincia de Buenos Aires. Problemáticas de la Arqueología Contemporánea (ed. por A. Austral y M. Tamagnini), pp. 565-573. Facultad de Ciencias Humanas, Universidad Nacional de Río Cuarto. Córdoba.

Pérez, M., I. Acosta, G. A. Naranjo \& L. S. Malec

2013 Uso de la alfarería y conductas alimenticias en el humedal del Paraná inferior a través del análisis de ácidos grasos. Cuadernos del Instituto Nacional de Antropología y Pensamiento Latinoamericano - Series Especiales 1 (1): 26-45

Pérez, M., D. Vigliocco, S. Ali y V. Di Pietro

2012 Decoración de cerámica en el humedal del Paraná inferior. Trabajo presentado en Simposio Paisajes Arqueológicos del Holoceno Tardío. Libro de Resúmenes, pp. 12. Departamento de Arqueología, Facultad de Humanidades y Artes, Universidad Nacional de Rosario.

Pérez, M., S. Ali, P. Bozzano y S. Domínguez

2015 Pigmentos de la cerámica del humedal del Paraná inferior: análisis físicoquímico MEB-EDX. Trabajo presentado en VI Encuentro de Discusión de Arqueología del 
Nordeste Argentino. Revista del Museo de La Plata, Arqueología 14 (89), pp. 42. Facultad de Ciencias Naturales y Museo, Universidad Nacional de La Plata.

Politis, G. G., y M. Bonomo

2012 La entidad arqueológica Goya-Malabrigo (ríos Paraná y Uruguay) y su filiación Arawak. Boletín de la Sociedade de Arqueologia Brasileira (SAB) 25 (1): 10-46.

Richerson, Py R. Boyd

2005 Not by genes alone. University of Chicago Press. Chicago.

Rodrigué, D.

2005 El estilo en la cerámica del Humedal del Paraná. La Zaranda de Ideas. Revista de jóvenes investigadores en Arqueología 1: 59-75.

Rye, O. S.

1981 Pottery technology: principles and reconstruction. Taraxacum. Washington, DC

Sackett, J. R.

1986 Isochrestism and style: a clarification. Journal of Anthropological Archaeology 5(3), 266-277.

Shennan, $\mathrm{S}$.

2003 Archaeological Approaches to Cultural Identity. Routledge, Londres.

Shennan, S. y J. Wilkinson

2001 Ceramic style change and neutral evolution: a case study from Neolithic Europe. American Antiquity 66: 577-593.

Schmidl, U.

1948 Crónica del viaje a las regiones del Plata, Paraguay y Brasil. Talleres Peuser S. A., Buenos Aires.

Silvestre, R. S., N. Buc, A. Acosta, y D. Loponte

2013 Estrategias de captura de presas y sistemas de armas de los cazadoresrecolectores que habitaron el humedal del Paraná inferior: una aproximación experimental y arqueológica. Comechingonia 17(1), 27-57.

Tchilinguirian, $\mathrm{P}$.

2013 Paleoambientes y paleogeografía en el humedal inferior del rio Paraná, Argentina: Una perspectiva geoarqueológica. Cuadernos del Instituto Nacional de Antropología y Pensamiento Latinoamericano - Series Especiales 1(3): 17-28.

Torres, L. M.

1911 Los primitivos habitantes del Delta del Paraná. Universidad Nacional de La Plata Biblioteca Centenaria. La Plata, Argentina.

Wiessner, $\mathrm{P}$.

1983 Style and social information in Kalahari San projectile points. American Antiquity 2: 253-276.

Wobst, H. M.

1977 Stylistic behavior and information exchange. Anthropological Paper 61: 317-342 